\title{
White Spaces in UHF Band: Catalonia Case Study and Impact of the Digital Dividend
}

\author{
Albert Domingo, Boris Bellalta, and Miquel Oliver \\ Universitat Pompeu Fabra de Barcelona \\ C/ Tànger 122-140, 08018 Barcelona, Spain \\ \{albert.domingo, boris.bellalta, miquel.oliver\} @upf .edu
}

\begin{abstract}
White Spaces in the UHF bands are very interesting because of their potential use in rural communications, but their feasibility needs to be proven. This paper analyses the TV spectrum occupation in the region of Catalonia, Spain, because it will be one of the first EU regions where changes in the UHF band are going to be implemented. Those changes are derived from the implementation of the Digital Dividend. The goal of this paper is to correlate population density with future free channel availability, and to proof that communications through TV White Spaces equipment is a good candidate for low density population areas.
\end{abstract}

Keywords: White Spaces, UHF, Digital Dividend, Spectrum availability.

\section{Introduction}

White Spaces -WS- is the term that refers to the non-occupied frequencies in the spectrum. In particular, bandwidth availability on the television broadcasting frequency bands is the focus of this paper. Both Very High Frequency -VHF- and Ultra High Frequency -UHF- are used, however, we will only focus on the UHF part of the spectrum.

The occupancy of those bands has been reduced after implementing the digital television signal, which uses less spectrum to provide more channels. Only when both signal types (analog and digital) were broadcasted over the same area it could be stated that the spectrum was scarce on the studied bands.

The high value of those frequencies is due to their physical properties and some attributes can describe why: they can cover large areas from a single emission point, they can penetrate physical objects in contrast to higher frequencies (e.g.: thick concrete/brick/stone walls) and thus improve the in-building signal strength, and costs over a covered area can decrease in comparison to other technological solutions based on higher frequencies. However, this will depend on the business model and policies implemented.

The Digital Dividend will bring a reduction in the UHF band usage and has been considered by the European Commission as a way of boosting the economic growth of the region [1]. The shift in spectrum will take place in TV channels from 61 to 69

R. Szabó and A. Vidács (Eds.): EUNICE 2012, LNCS 7479, pp. 33-40, 2012.

C IFIP International Federation for Information Processing 2012 
(790 MHz to $862 \mathrm{MHz}$ ). Previous to the Digital Dividend the Commission resolved to take part of the spectrum released by the digital switchover, as shown in their paragraphs 30 to 37, to promote among the European countries special licenses for White Space frequencies [2].

This paper aims to study if there will be differences between rural and urban areas in the usage of these frequencies. It contributes to understand the availability of WS, taking into account the Digital Dividend, and the possible link established between inhabitants density and spectrum availability, something that would complete the study made in [3] by focusing the area of study. Our contribution in this area is to assure feasibility for rural areas and to allow new standards of communication to be deployed taking advantage of WS.

This paper is structured as follows. We first describe in Section 2 the evolution of the UHF band in Spain until the Digital Dividend will be applied. Section 3 describes the methodology followed to obtain the results for UHF spectrum availability in Catalonia. Main results are shown in Section 4. Our conclusions are given in Section 5 which also includes some future work that we will carry on in the same area.

\section{Evolution of the UHF Band in Spain}

Spain was the forth country adopting Digital Television and the third to implement it (the first countries to adopt it were USA, UK, and Sweden. Implementation had the same actors but Spain installed the required infrastructure before Sweden).

Spain started to assign digital television channels in 1999. Different levels of granularity were used to assign the channels: State, Regional and Local levels.

The digital switchover in Spain has come with a reduction of the local television coverage, where most of the cities, towns and villages were broadcasting a local signal with content based on local interest.

Televisió de Catalunya carried out the first emission in Spain in 1998 under a trial license. Then, in 1999 Onda Digital S.L., which since has been re-named Quiero TV, obtained the first private license to broadcast 14 channels [4]. Those channels included all the satellite contents and were offered under the pay-per-view option.

Some problems arose in Spain after the launch because the payment platform was not having the expected take-up rate, which lead to its closure in 2002. After this first end of digital TV, public television started broadcasting their content as a digital signal.

Spain started to design its digital transition in 2005 [5]. In July of the same year the Implementation Plan was published. In 2007, the transition plan was ratified and it was planned that before April 2010, all the analog TV channels should be switched off [6].

As the digital switchover came closer, it was necessary to accept that $1,5 \%$ of the population would not receive the digital signal and a law was passed to fix this problem by using satellites to broadcast the service [7].

The implementation of the European mandate of its article 6 to free the spectrum around $800 \mathrm{MHz}$, called Digital Dividend, for providing digital communications over those frequencies is the current channel switching that will be applied to the UHF band ([8] and [9]). Spain has implemented this directive in its law and wants to make available channels from 61 to 69 ( $790 \mathrm{MHz}$ to $862 \mathrm{MHz}$ ) before January 1st, 2015. According to the European Union, this should allow new possibilities for rural areas and less favoured users. 
As long as this spectrum was seen by regulation as TV bands, it has never been allowed to be used for anything else than broadcasting television in Spain. Before 2009, FCC, OFCOM and private companies were doing research on this area and conducted real-life tests (see [10], [11], [12] and [13]). Currently, there are some standards suitable to be implemented for those frequencies that can operate within a UHF channel (e.g.: LTE, 802.22 and 802.11af). Regulation will be applied to guarantee that no interference is seen on the TV licensed channels and to model the use of the WS. Some research is done on the use of beacons to announce a free TV channel [14], and on the use of a sensor to find WS which would be defined under cognitive equipment [15]. The interest of our research is the implementation of a database that informs about channel availability in every area [16].

\section{$3 \quad$ Methodology and Example to Predict Availability}

In Spain the use of licensed-free equipment is not allowed in the UHF bands as it is only permitted on the ISM ${ }^{1}$ bands defined by the ITU-T. Currently, the Spanish TV band is only operated under license requirement.

To identify the unused channels, we first included the licensed channels per area. Such information is obtained from official published sources. National channels are licensed directly from the "Ministerio de Industria, Energía y Turismo", which has a section devoted to allocate and assign frequencies that is held by the "Secretaria de Estado de las Telecomunicaciones". As this first study is focusing on Catalonia, we have to consult and add the Catalan regional channels that are licensed by the "Generalitat de Catalunya". Finally we have also checked all the local televisions that are broadcasted in the region.

The number of occupied channels is obtained after adding the 9 channels that will be devoted to LTE communications and will reduce the Digital Dividend. After that we have also added the number of occupied channels that cognitive equipment can sense, between 4 and 6 more channels than the licensed ones. Finally, an approximation of the worst case for the area is done by adding 4 interference channels licensed in neighbouring areas of the analysed region. This is done because the strength of their signals usually covers more area than the city, town or village where they were licensed.

As an example of our study we show the results for the dense urban Barcelona area in Table 1, and a detailed list of the channel's occupancy is shown in the Appendix.

It can be seen in Table 1 that the effect of the Digital Dividend on the number of available channels in Barcelona will suffer a decrease from 27 to 12 according to our predictions for the year 2015. The equivalent space in $\mathrm{MHz}$ for WS is set around 96 $\mathrm{MHz}$, which is more than the $60 \mathrm{MHz}$ freed by the Digital Dividend on the band of $800 \mathrm{MHz}$ [17].

\footnotetext{
${ }^{1}$ Industrial Scientific and Medical radio bands defined by the International Telecommunication Union Radiocommunication - ITU-R. European, Region 1, UHF IMS band is set at 433.05 to 434.79 MHz.
} 
The middle column was obtained by using a Promax spectrum analyzer, model AE-766, to verify in-the-field the real channel occupancy. The result was that some channels were occupied without being licensed and some licensed channels were not broadcasting on that day. This result is similar to what would be sensed by cognitive equipment [18].

Table 1. Barcelona area occupancy results

\begin{tabular}{cccrr}
\hline & $\begin{array}{c}\text { Current } \\
\text { channels Feb 2012 }\end{array}$ & $\begin{array}{c}\text { licensed } \\
\text { cheasurement 2012 }\end{array}$ & $\begin{array}{c}\text { Observed } \\
\text { mer year 2015 }\end{array}$ \\
\hline Occupied channels & 18 & 14 & 25 \\
Occupancy percentage (\%) & 36,7 & 28,6 & 61,0 \\
Availability percentage (\%) & 63,3 & 71,4 & 39,0 \\
Free channels & 31 & 35 & 16 \\
Approximation of free channels & 27 & 31 & 12 \\
Availability approximation percentage (\%) & 55,1 & 63,3 & 29,3 \\
\hline
\end{tabular}

Regional interference approximation (-4 channels). These interferences come from local channels that are emitting in the surroundings of Barcelona and that can affect the region. Therefore, if cognitive radio equipment is applied it will show occupancy in those channels.

\section{Current and Future Availability: Population Density and UHF Channels in the Region of Catalonia}

The same methodology that is used in Section 3 can be extended to any other region where the Digital Dividend is going to be applied. Our approximation of availability inside the UHF band after 2015 is shown in Figure 1.a). It shows the number of 8 $\mathrm{MHz}$ spaced channels available, superimposed over the Catalonia map.

It can be discerned that the occupancy is higher in the city of Barcelona and its surroundings. There will be only between 12 and 14 channels available to implement WS communication solutions. The same situation occurs on the borders of the region. In those cases the interference of other regional TV channels (those of Aragon and the Comunitat Valenciana) will increase the occupied channels to levels of big cities like Barcelona. The Catalan central region and the north, with the Pyrenees, will have less interference and will have an average amount of free channels between 15 and 16 . The case of Andorra, also analysed, shows that 22 channels will be available there and is the best case analysed after applying the methodology described in Section 3.

As we want to know future availability per user we include the inhabitant density map $^{2}$, Figure 1.b), to be compared with the WS availability map. High density areas are defined with more than 1000 inhabitants per square kilometre and rural ones with less than 150 inhabitants per square kilometre.

If we compare the density map and the availability map, only the boarders with other regions do not show a correlation with population density. From that point of

${ }^{2}$ Map extracted from “Anuari Estadístic de l'Institut Cartogràfic de Catalunya”, by C. Marti and J. Feliu. and created with data from 2007. 
view, without quantification, it would seem suitable to state that the use of WS could have a bigger effect in rural areas than in urban ones.

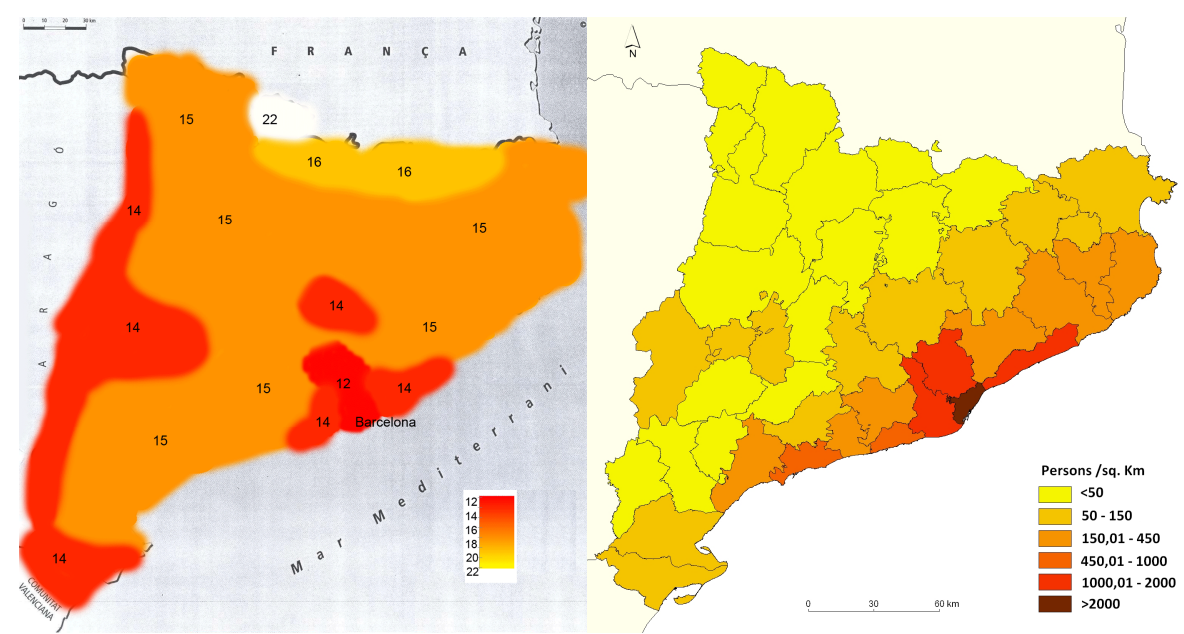

Fig. 1. 2015 Catalonian UHF channel availability map made by the authors (left map) and Catalan density map (right map), white or yellow areas are for density below 50 inhabitants per square $\mathrm{km}$ and black or red areas for densities higher than 1000 inhabitants per square $\mathrm{km}$

To quantify the relation between the two maps the best availability per person has been calculated. Table 2 shows that the average number of available channels is higher in rural areas than in urban ones, as expected from the observed data. Rural areas will have the best availability of $2.26 \mathrm{MHz}$ per person, compared to the worst availability of $0.05 \mathrm{MHz}$ per person in dense urban areas.

Table 2. Mega Hertz availability in WS after Digital Dividend is applied in 2015 in Catalonia

\begin{tabular}{ccc}
\hline & Rural & Urban \\
\hline MHz available per inhabitant & 2.26 to $0.80 \mathrm{MHz} /$ person & 0.11 to $0,05 \mathrm{MHz} /$ person \\
Inhabitants in each $\mathrm{Km}^{2}$ & 50 to 150 inhabitants & 1000 to 2000 inhabitants \\
Channels available in 2015 & 15 to 16 channels & 12 to 14 channels \\
\hline
\end{tabular}

\section{Conclusions and Future Work}

In this paper, we have shown that even after the Digital Dividend is applied, there will be available UHF channels beyond 2015. We have shown that the relation between the number of inhabitants and the number of available channels (i.e., more inhabitants means less WS) also holds in the Catalan region, with $2.26 \mathrm{MHz}$ per inhabitant in rural areas in contrast to the $0.05 \mathrm{MHz}$ per inhabitant in urban ones. Finally, the results have shown that the use of a database to avoid interferences with licensed channels is highly recommended. However, as some of the licensed channels were not 
found during our spectrum measurements, which was acting like cognitive equipment and, on the other hand, we found occupied channels that were supposed to be not in use. This shows that cognitive radio has to be combined with a list of licensed channels to regulate a solution that do not affect the current UHF TV channels.

This paper opens the door to a policy that will enable for the first time in Spain the use of exchanging data in an entire UHF channel, although the creation of a database and a license manager would be the first step to implement WS equipment.

A further study over the Spanish region is currently undertaken by us to obtain a better relation between rural areas, urban areas and their availability of spectrum. Currently, 83 Spanish regions have been analysed, and the average result is close to the one shown in the Barcelona area with an average number of 14 available channels, which supposes an averaged free spectrum of $112 \mathrm{MHz}$ in the Spanish UHF band.

The conclusions obtained for the Region of Catalonia, but also for the current research over Spain, a larger area, makes that the results obtained in here will also be extended to European regions were the same amount of spectrum is devoted to television inside the UHF band.

Acknowledgments. This work was partially supported by the Spanish government and by the European Commission through the projects GEPETO (TEC2008-06055/TEC) and Commons for Europe (CIP-ICT-PSP-2011-5-297191), respectively.

\section{References}

1. European Commission: 586 final: Transforming the digital dividend opportunity into social benefits and economic growth in Europe. Brussels (2009)

2. European Commission: Resolution: Common approach to the use of the spectrum released by the digital switchover. Brussels (2008)

3. van de Beek, J., Riihijarvi, J., Achtzehn, A., Mähönen, P.: UHF white space in Europe - a quantitative study into the potential of the 470-790 MHz band. In: IEEE International Symposium on Dynamic Spectrum Access Networks, Aachen (2011)

4. del Estado, B.O.: RESOLUCIÓN de 2 de septiembre de 1999, de la Secretaría General de Comunicaciones, por la que se hace público el Acuerdo del Consejo de Ministros de 18 de junio de 1999 por el que se resuelve el concurso público convocado para la adjudicación de una concesión habilitante para la explotación del servicio de televisión digital terrenal. BOE-232, 34577 (1999)

5. del Estado, B.O.: LEY 10/2005, de 14 de junio, de Medidas Urgentes para el Impulso de la Televisión Digital Terrestre, de Liberalización de la Televisión por Cable y de Fomento del Pluralismo. BOE-142, 20562-20567 (2005)

6. Ministerio de Industria y Comercio: Acuerdo del consejo de ministros por el que se aprueba el plan nacional de transición a la televisión digital terrestre, Madrid (2007)

7. del Estado, B.O.: LEY 7/2009, de 3 de Julio, de medidas urgentes en materia de telecomunicaciones, que regula la cobertura complementaria de los canales de TDT mediante, al menos, una plataforma común satelital. BOE-161, 55729-55732 (2009) 
8. European Commission: Communication from the commission to the European parliament, the council, the European economic and social committee and the committee of the regions. A Digital Agenda for Europe, Brussels (2010)

9. European Commission: Commission Decision of 6 May 2010 on harmonised technical conditions of use in the $790-862 \mathrm{MHz}$ frequency band for terrestrial systems capable of providing electronic communications services in the European Union. Notified under document C(2010) 2923, Text with EEA relevance, Brussels (2010)

10. Chandra, R., Moscibroda, T., Bahl, P., Murty, R., Nychis, G., Wang, X.: A campus-wide testbed over the TV white spaces. SIGMOBILE Mob. Comput. Commun. Rev. 15 (2011)

11. Davies, R., Ghosh, M.: Field Trials Of DVB-T Sensing For TV White Spaces. In: IEEE International Symposium on New Frontiers in Dynamic Spectrum Access Networks (2011)

12. Federal Communication Commission: SECOND MEMORANDUM OPINION AND ORDER in the matter of Unlicensed Operation in the TV Broadcast Bands and Additional Spectrum for Unlicensed Devices Below $900 \mathrm{MHz}$ and in the $3 \mathrm{GHz}$ Band. FCC, Washington (2010)

13. Office of Communication: Statement: Digital dividend: cognitive access Statement on licence-exempting cognitive devices using interleaved spectrum. OFCOM (2009)

14. Goratti, L., Baldini, G., Rabbachin, A.: An Urn Occupancy Approach for Cognitive Radio Networks in DTVB White Spaces. In: Sacchi, C., Bellalta, B., Vinel, A., Schlegel, C., Granelli, F., Zhang, Y. (eds.) MACOM 2011. LNCS, vol. 6886, pp. 24-38. Springer, Heidelberg (2011)

15. Shin, K.G., Kim, H., Min, A., Kumar, A.: Cognitive Radios for Dynamic Spectrum Access: From Concept to Reality. IEEE Wireless Comms. Magazine (IEEE WCM), vol. 17(6) (2010) (invited paper)

16. Federal Communication Commission: Public Notice: FCC's Office of Engineering and Technology Issues Public Notice to Start Public Testing for Spectrum Bridge's TV White Spaces Database System, Washington (2011)

17. European Commission: Decision of the European Parliament and of the Council establishing the first radio spectrum policy programme, Brussels (2010)

18. Institute of Electrical and Electronics Engineers: IEEE Standard for Wireless Regional Area Networks Part 22: Cognitive Wireless RAN Medium Access Control (MAC) and Physical Layer (PHY) specifications: Policies and procedures for operation in the TV Bands, New York (2011)

\section{Appendix: Methodology Example}

This Appendix is an example of our methodology and how we have assumed the possible 2015 spectrum availability. We have taken into account three different columns. The first one is the official licensed channels occupancy that would be the official database. The second column exposes the values obtained with measurement equipment at UPF on February of 2012 that would act as cognitive equipment. The last column relates our approximated channel availability, also considered as a forecast of occupancy for 2015. Table 1, in Section 3, shows Table A results. 
Table A. Barcelona channel occupancy analysis. A number 1 in the grid identifies occupation

\begin{tabular}{|c|c|c|c|c|c|}
\hline Channel & Video frequency & $\begin{array}{l}\text { Barcelona } \\
\text { Licensed } 2012\end{array}$ & $\begin{array}{l}\text { Observed } \\
2012\end{array}$ & measures & $\begin{array}{l}\text { UPF forecast for } \\
\text { year } 2015\end{array}$ \\
\hline 21 & 471.25 & & & & \\
\hline 22 & 479.25 & & & 1 & 1 \\
\hline 23 & 487.25 & 1 & & & 1 \\
\hline 24 & 495.25 & & & 1 & 1 \\
\hline 25 & 503.25 & & & & \\
\hline 26 & 511.25 & 1 & & & 1 \\
\hline 27 & 519.25 & 1 & & 1 & 1 \\
\hline 28 & 527.25 & & & & \\
\hline 29 & 535.25 & 1 & & 1 & 1 \\
\hline 30 & 543.25 & & & & \\
\hline 31 & 551.25 & 1 & & & 1 \\
\hline 32 & 559.25 & & & 1 & 1 \\
\hline 33 & 567.25 & 1 & & & 1 \\
\hline 34 & 575.25 & 1 & & & 1 \\
\hline 35 & 583.25 & & & & \\
\hline 36 & 591.25 & 1 & & & 1 \\
\hline 37 & 599.25 & & & & \\
\hline 38 & 607.25 & & & & \\
\hline 39 & 615.25 & & & & \\
\hline 40 & 623.25 & & & & \\
\hline 41 & 631.25 & & & & \\
\hline 42 & 639.25 & & & 1 & 1 \\
\hline 43 & 647.25 & 1 & & & 1 \\
\hline 44 & 655.25 & 1 & & & 1 \\
\hline 45 & 663.25 & & & & \\
\hline 46 & 671.25 & 1 & & & 1 \\
\hline 47 & 679.25 & 1 & & 1 & 1 \\
\hline 48 & 687.25 & 1 & & & 1 \\
\hline 49 & 695.25 & & & & \\
\hline 50 & 703.25 & & & & \\
\hline 51 & 711.25 & & & 1 & 1 \\
\hline 52 & 719.25 & & & 1 & 1 \\
\hline 53 & 727.25 & & & & \\
\hline 54 & 735.25 & & & & \\
\hline 55 & 743.25 & & & & Channel 61 \\
\hline 56 & 751.25 & & & & Channel 64 \\
\hline 57 & 759.25 & & & 1 & 1 \\
\hline 58 & 767.25 & & & & Channel 67 \\
\hline 59 & 775.25 & & & & Channel 68 \\
\hline 60 & 783.25 & & & & Channel 69 \\
\hline 61 & 791.25 & 1 & & & Dig. Dividend \\
\hline 62 & 799.25 & & & & Dig. Dividend \\
\hline 63 & 807.25 & & & & Dig. Dividend \\
\hline 64 & 815.25 & 1 & & 1 & Dig. Dividend \\
\hline 65 & 823.25 & & & & Dig. Dividend \\
\hline 66 & 831.25 & & & & Dig. Dividend \\
\hline 67 & 839.25 & 1 & & 1 & Dig. Dividend \\
\hline 68 & 847.25 & 1 & & 1 & Dig. Dividend \\
\hline 69 & 855,25 & 1 & & 1 & Dig. Dividend \\
\hline
\end{tabular}

